\title{
HUBUNGAN PENGETAHUAN DENGAN PELAKSANAAN ASUHAN KEPERAWATAN
}

\author{
ANGEL OKTAVIA PURBA / 181101099 \\ angeloktavia013@gmail.com
}

\begin{abstract}
ABSTRAK
Tindakan keperawatan atau implementasi adalah tahap etika perawat mengaplikasikan rencana asuhan keperawatan kedalam bentuk intervensi keperawatan guna membantu klien mencapai tujuan yang telah ditetapkan. Tujuan dari penulisan ini adalah untuk mengetahui defenisi implementasi, tujuan dilakukannya implementasi, dan bagaimana pelaksanaan tahap impleme ntasi . Metode penulisan ini adalah Literature Riview, dimana ini menganalisis artikel yang relevan dan berfokus pada tema tahap implementasi keperawatan.
\end{abstract}

Hasil, Berdasarkan pencarian literature didapatkan apa itu defenisi implementasi keperawatan atau tindakan keperawatan, apa saja tujuan dilakukannya implementasi keperawatan dan bagaimana pelaksaanaan tahap implementasi.

Kata Kunci : Proses keperawatan, Implementasi keperawatan, Pengetahuan keperawatan dalam implementasi

\begin{abstract}
Nursing action or implementation is the ethical stage of the nurse applying the nursing care plan into the form of nursing interventions to help clients achieve their stated goals. The purpose of this paper is to determine the definition of implementation, the purpose of the implementation, and how the implementation phase of implementation. This writing method is Riview Literature, where it analyzes relevant articles and focuses on the theme of the nursing implementation stage.

Results, Based on the literature search, what is the definition of nursing implementation or nursing action, what are the objectives of nursing implementation and how is the implementation phase.
\end{abstract}

Keywords: Nursing process, Nursing implementation, Nursing knowledge in implementation 


\section{LATAR BELAKANG}

Dalam proses keperawatan terdapat beberapa tahapan proses keperawatan yaitu pengkajian, diagnose, perencanaan, implementasi dan evaluasi. Setiap tahap proses keperawatan saling terkait dan ketergantungan satu sama lain. Untuk itu dalam memberikan asuhan keperawatan tentunya seorang perawat harus melaksanakan tahap-tahap dalam proses keperawatan tersebut secara benar dan tepat agar tidak terjadi kesalahan sehingga asuhan keperawatan yang diberikan dapat berjalan secara optimal. Tahap yang dilakukan setelah melakukan atau menyelesaikan tahap perencanaan dalah tahap implementasi, Implementasi keperawatan adalah serangkaian kegiatan yang dilakukan oleh perawat untuk membantu klien dari masalah status kesehatan yang dihadapi kestatus kesehatan yang lebih baik yang menggambarkan kriteria hasil yang diharapkan Pada saat implementasi perawat harus melaksanakan hasil dari rencana keperawatan yang di lihat dari diagnosa keperawatan. Di mana perawat membantu klien dari masalah status kesehatan yang dihadapi kestatus kesehatan yang lebih baik yang menggambarkan kriteria hasil yang diharapkan. Sehingga, dengan proses keperawatan, rasa tanggung jawab dan tanggung gugat bagi perawat itu dapat dimiliki dan dapat digunakan dalam tindakan-tindakan yang merugikan atau menghindari tindakan yang legal. Semua tatanan perawatan kesehatan secara hukum perlu mencatat observasi keperawatan, perawatan yang diberikan, dan respons pasien.

\section{TUJUAN}

Tujuan dari penulisan ini adalah untuk mengetahui defenisi implementasi, tujuan dilakukannya implementasi, dan bagaimana pelaksanaan tahap impleme ntasi .

\section{METODE}

Metode penulisan ini adalah Literature Riview, dimana ini menganalisis artikel yang relevan dan berfokus pada tema tahap implementasi keperawatan. Adapun sumber yang digunakan dalam literature ini menggunakan sumber dari buku teks, jurnal dengan memasukan kata kunci implementasi dalam proses keperawatan. Adapun jurnal yang saya yang digunakan merupakan jurnal yang diiterbitkan pada 10 tahun terakhir.

\section{HASIL}

Berdasarkan pencarian literature didapatkan apa itu defenisi implementasi keperawatan atau tindakan keperawatan, apa saja tujuan dilakukannya implementasi keperawatan dan bagaimana pelaksaanaan tahap implementasi keperawatan. 


\section{PEMBAHASAN}

Tindakan keperawatan atau implementasi adalah tahap etika perawat mengaplikasikan rencana asuhan keperawatan kedalam bentuk intervensi keperawatan guna membantu klien mencapai tujuan yang telah ditetapkan. Kemampuan yang dimiliki perawat pada tahap implementasi adalah kemampuan komunikasi yang efektif, kemampuan untuk mencitakan hubungan saling percaya san saling membantu, kemampuan melaukukan teknik psikomotor, kemampuan melakukan observasi sistematis, kemampuan memberikan pendidikan kesehatan, kemampuan advokasi, dan kemampuan evaluasi. Tujuan utama implementasi adalah untuk melaksanakan rencana yang telah disusun dengan cermat, oleh perawat.

Intervensi keperawatan terdiri dari tiga fase yaitu :

Fase pertama merupakan fase persiapan yang mencakup pengetahuan tentang validasi rencana, implementasi rencana, persiapan klien dan keluarga.

Fase kedua merupakan puncak implementasi keperawatan yang berorientasi pada tujuan. Pada fase ini perawat berusaha menyimpulkan data yang telah dihubu8ngkan dengan reaksi klien. Fase ketiga merupakan terminasi perawat-klien setelah implementasi keperawatan selesai dilakukan. Langkah selanjutnya adalah menyimpulkan hasil pelasanaan intervensi keperawatan tersebut. Implementasi tindakan keperawatan terbagi menjadi tiga kategori, yaitu independent, Interdependent, dan dependent: -Independent, yaitu suatu kegiatan yang dilaksanakan oleh perawat tanpa petunjuk dari dokter atau tenaga kesehatan lainnya. Lingkup tindakan keperawatan independen, antara lain :

- Mengkaji klien atau keluarga melalui riwayat keperawatan dan pemeriksaan fisik untuk mengetahui status kesehatan klien.

- Merumuskan diagnose keperawatan sesuai respond klien yang memerlukan intervensi keperawatan.

- Mengidentifikasi tindakan keperawatan untuk mempertahankan atau memulihkan kesehatan klien.

- Mengevaluasi respond klien terhadap tiindakan keperawatan dan medis 
-Interdependent, yaitu suatu kegiatan yang memerlukan kerja sama dengan tenaga kesehata lainnya.

-Dependen, berhubungan dengan pelaksanaan rencana tindakan medis/instruksi dari tenga medis.

Faktor-faktor yang mempengaruhi pelaksanaan keperawatan antara lain :

a.Kemampuan intelektual, teknikal, dan interpersonal.

b.Kemampuan menilai data baru.

c. Kreativitas dan inovasi dalam memodifikasi rencana tindakan.

d. Penyesuaian selama berinteraksi dengan klien.

e.Kemampuan mengambil keputusan dalam memodifikasi pelaksanaan. f.Kemampuan untuk menjamin kenyamanan dan keamanan serta efektivitas tindakan.

Adapun tahap-tahap dalam pelaksanaan tindakan keperawatan antara lain sebaagai berikut :

a)Tahap persiapan

- Review rencana tindakan keperawatan.

- Analilis pengetahuan dan keterampilan yang diperlukan.
- Anatisispasi komplikasi yang akan timbul.

- Mempersiapkan peralatan (waktu,tenaga, alat).

- Mengidentifikasi aspek-aspek hukum dan etik.

- Memperhatikan hak pasien antara lain ha katas pelayanan kesehatan sesuai dengan standart pelayanan kesehatan, hak atas informasi, hak untuk menentukan nasib sendiri, dan ha katas second opinion.

b)Tahap pelaksanaan

- Berfokus pada klien.

- Berorientasi pada tujuan dan kriteria hasil.

- Memperhatikan keamanan fisik dan psikososial klien.

- Kompeten.

c)Tahap sudah selesai

- Menilai keberhasilan tidakan.

- Mendokumentasikan tindakan yang meliputi tindakan aktivitas keperawatan, hasil /respon pasien, tanggal/jam, nomor diagnosis keperawatan, dan tanda tangan. 
Hal lain yang tidak kalah penting pada tahap implementasi adalah mengevaluasi respond atau hasil dari tindakan keperawatan yang dilakukan terhadap klien serta mendokumentasikann semua tindakan yang telah dilaksanakan.

\section{KESIMPULAN}

Tindakan keperawatan atau implementasi adalah tahap etika perawat mengaplikasikan rencana asuhan keperawatan kedalam bentuk intervensi keperawatan guna membantu klien mencapai tujuan yang telah ditetapkan. Kemampuan yang dimiliki perawat pada tahap implementasi adalah kemampuan komunikasi yang efektif, kemampuan untuk mencitakan hubungan saling percaya san saling membantu, kemampuan melaukukan teknik psikomotor, kemampuan melakukan observasi sistematis, kemampuan memberikan pendidikan kesehatan, kemampuan advokasi, dan kemampuan evaluasi. Tujuan utama implementasi adalah untuk melaksanakan rencana yang telah disusun dengan cermat, oleh perawat. Implementasi tindakan keperawatan terbagi menjadi tiga kategori, yaitu independent, Interdependent, dan dependent

\section{SARAN}

Perawat harus meningkatkan pemahamannya terhadap berbagai cara implementasi keperawatan sehingga dapat dikembangkan dalam tatanan layanan keperawatan. Diharapkan agar perawat bisa menindak lanjuti implementasi tersebut melalui kegiatan asuhan keperawatan sebagai dasar untuk pengembangan kedisiplinan di Lingkungan Rumah Sakit dalam ruang lingkup keperawatan.

\section{DAFTAR PUSTAKA}

Allen, C. V. (1998). Memahami Proses

Keperawatan. Jakarta. EGC.

Asmadi. (2008). Konsep Dasar Keperawatan. Jakarta. EGC.

Budiono \& Sumirah,B,P.(2016). Konsep Dasar Keperawatan (Ed 2). Jakarta. Bumi Medika.

Dermawan, Deden. (2012). Proses Keperawatan : Penerapan Konsep Dan Kerangka Kerja. Yogyakarta : Gosyen Publishing. 
Deswani. (2009). Proses Keperawatan dan Berpikir Kritis. Jakarta : Salemba Medika.

Doengens, M. E., Mary, F. M \& Alice, C. G. (1999). Rencana Asuhan Keperawatan ed 3. Jakarta. EGC.

Haryanto. (2007). Konsep Dasar Keperawatan Dengan Peemetaan Konsep. Jakarta : Salemba Medika.

Hidayat, A. Aziz Alimut. (2004). Pengantar Konsep Dasar Kepperawatan. Jakarta. Salemba Medika.

Lismidar,H.(1990).Proses

Keperawatan. Jakarta : Universitas Indonesi.

Potter \& Perry. (2005). Buku Ajar Fundamental Keperawatan Konsep Proses Dan Praktik Edisi 4. Jakarta : EGC.

Potter \& Perry. ( 2010). Fundamental Of Nursing : Edisi 7. Jakarta : EGC.

Rohma, N \& Wahid, S. (2009). Proses Keperawattan. Arruz Media.
Roper, Nancy. (1996). Prinsip-Prinsip Keperawatan. Yogyakarta : Andi Yayasan Essentia Medica.

Simamora, R. H. (2009). Dokumentasi keperawatan. Jamber University Press.

Simamora, R. H. ( 2010). Komunikasi Dalam Keperawatan. Jamber University Press.

Simamora, R. H. (2008). Peran Manajemen Pembinaan Etika Perawat Pelaksanan Dalam Peningkatan Kualitas Pelayanan Asuhan Keperawatan. Jurnal IKESMA.

Tarwoto \& Wartonah. (2012). Kebutuhan Dasar Manusia Dan Proses Keperawatan. Jakarta : Salemba Medika. 